Journal of Food Technology 8 (3): 74-81, 2010

ISSN: $1684-8462$

(C) Medwell Journals, 2010

\title{
Halal Traceability and Halal Tracking Systems in Strengthening Halal Food Supply Chain for Food Industry in Malaysia (A Review)
}

\author{
Suhaiza Zailani, Zainal Arrifin, Nabsiah Abd Wahid, Rosly Othman and Yudi Fernando \\ School of Management, University Sains Malaysia, 11800, Penang, Malaysia
}

\begin{abstract}
The Halal industry involves farm-to-table operations. This has led to the development of new links within the value chain most notably in the area of information technology. Given the advancement in science and technology and the on-going initiatives to improve society, it is essential that the Halal concept be fully understood by industry players as well as customers. Halal traceability system and Halal tracking system are emerging as lucrative areas in the global Halal market. An effective traceability and tracking system in Malaysia is essential to mitigate the risks associated with Halal that can disrupt the international trade of Malaysian Halal food. Traceability and tracking systems function as a tool for communication making information available along the supply chain. However, recently Malaysia's latest claim to be one of the Halal hubs in the world was put to test due to the unbelievable result of recent raid carried out by the Malaysia authorities. The finding was appalling and unethical as some so-called Halal foods manufacturers do not comply with the regulation set by the Malaysia authorities. The commotion pertaining to this issue was immense where the Muslim consumers in Malaysia began to question the effectiveness of Halal food traceability and tracking in Malaysia's market. This study is written to discuss on the approaches towards Halal traceability and tracking currently used in Malaysia. Specifically, this study discusses the conceptual architecture on Halal traceability and Halal tracking system for Halal food product in Malaysia.
\end{abstract}

Key words: Halal food supply chain, Halal traceability, tracking system, goods industry, product, Malaysia

\section{INTRODUCTION}

The quality of life of human beings can be significantly enhanced by the availability of food required for nourishment and sustenance. For Muslims, it is very important that the food consumed must be Halal and free from tainted elements. Given the speed of trade globalization the advancement in science and technology and the on-going initiatives to improve society, it is essential that the Halal concept be fully understood by both industry players and customers alike. It is important to appreciate how the Halal concept will influence the transformation of society towards achieving a better quality of life. Generally, the quality of life is influenced by dimensions which include education, food, employment, energy, environment, health, human rights, income, infrastructure, national security, public safety, re-creation and shelter (Henderson, 2001). Food safety and its quality assurance are very important to many people around the world. The last few decades have shown that society is placing such issues on top of everything else mainly because of the changes in eating habit, values and beliefs. Due to the higher volume of food trade between countries (Bates, 2004). Following this, several changes in the operating environment of the food and agribusiness sectors have contributed to rising interest in Halal food supply chain. Halal food supply chain provides a means to conceptualize Halal in the system to efficiently respond to consumer needs based on integration and co-ordination of the efforts of all the business units involved in the production and delivery processes such as at farm input farm, processor and supermarket levels (Riaz and Chaudry, 2004). At the consumer level, the driving forces changing agribusiness comprise increased consumers sensitivity to quality, safety, health and nutritional aspects of food products and their interests in the place of origin of the food produced, the means of production used including non-food values such as environmental sustainability and animal welfare. By taking into consideration the perspectives of the consumers, the Halal concept can be regarded as a catalyst that can transform people's way of life but also their ideas and interpretations of quality, health, safety and environment. As with other religions in the world, Islam has introduced clear and definite concepts of Halal and haram that its followers must adhere to. Many of the Islamic teachings are based on these concepts and their manifestations can be observed in the areas of everyday production and consumption of food and other products. As Muslims, the concepts of Halal and haram in food consumption are

Corresponding Author: Suhaiza Zailani, School of Management, University Sains Malaysia, 11800, Penang, Malaysia 
paramount. Now a days more Muslims are becoming more diligent in observing their dietary obligations. This is in line with the teachings of Islam as highlighted in the Quran:

So eat of the lawful and good food which Allah hath provided for you and thank the bounty of your Lord if it is Him ye serve. He hath forbidden for you only carrion, blood, swine-flesh and that which hath been immolated in the name of any other than Allah... (An Nahl, 16:114-116)

However, recently Malaysia's latest claim to be one of the Halal hubs in the world was put to test due to the unbelievable result of recent raid carried out by the Malaysia authorities. The finding was appalling and unethical as some so-called Halal foods manufacturers do not comply with the regulation set by the Malaysia authorities. The commotion pertaining to this issue was immense where the Muslim consumers in Malaysia began to question the effectiveness of Halal food traceability in Malaysia's market. This study is to discuss on how Malaysia is trying to strengthen the Halal food supply chain through technology in order to protect Muslim consumer in the market. The goal of the study is to analyse the status and perspectives of Halal traceability and tracking systems. The study describe the importance of traceability in food supply chain and follows by Halal traceability and Halal tracking purposes, requirements and status. The economic research agenda for the field of Halal traceability and Halal tracking systems in livestock production chains ends the study.

\section{FOOD SUPPLY CHAIN}

Supply-chain management simply refers to the management of the entire set of production, distribution and marketing processes by which a consumer is supplied with a desired product.

Folkerts and Koehorst (1998) define a supply chain as a set of interdependent companies that work closely together to manage the flow of goods and services along the value-added chain of agricultural and food products in order to realize superior customer value at the lowest possible costs.

During the $1990 \mathrm{~s}$, academic and commercial interest in Supply-Chain Management (SCM) in agribusiness has risen significantly in Europe and the USA (Wood, 2004). The concept and its application have become one of the key areas of research and commercial focus in agribusiness for the past decade. The driving forces changing on new application to agribusiness include increasing consumers sensitivity to quality, safety, health and nutritional aspects of food products and their interest in the place of origin and means of production including non-food values such as environmental sustainability and animal welfare. The six principles of SCM used to measure the success of a supply chain for agricultural products in Malaysia are understanding and meeting customers and consumers needs, getting the products right, creating and sharing values, logistics and distribution, information and communication and effective relationships among supply-chain members.

Supply-chain management simply refers to the management of the entire set of production, distribution and marketing processes by which a consumer is supplied with a desired product. Folkerts and Koehorst (1998) define a supply chain as:

...A set of interdependent companies that work closely together to manage the flow of goods and services along the value-added chain of agricultural and food products, in order to realize superior customer value at the lowest possible costs

Importance of traceability and tracking in food supply chain: The ability to trace and follow a food, feed, food-producing animal or substance intended to be incorporated into a food or feed, through all stages of production, processing and distribution. Opara (2003) defines traceability in an agricultural context as: The collection, documentation, maintenance and application of information related to all processes in the supply chain in a manner that provides guarantee to the consumer and other stakeholders on the origin, location and life history of a product as well as assisting in crises management in the event of a safety and quality breach (Fig. 1).

With respect to a food product, traceability represents the ability to identify the farm where it was grown and sources of input materials as well as the ability to conduct full backward and forward tracking to determine the specific location and life history in the supply chain by means of records. Opara (2003) further recommends that for agriculture and food businesses an integrated supply chain traceability system must encompass the following elements:

- Product traceability to determine the physical location of items at any stage in the supply chain to facilitate recall and/or dissemination of information to customers and consumers

- Process traceability to determine the type and sequence of events that have occurred during the production and handling of the product: what, where, when. These include: physical/mechanical, chemical 


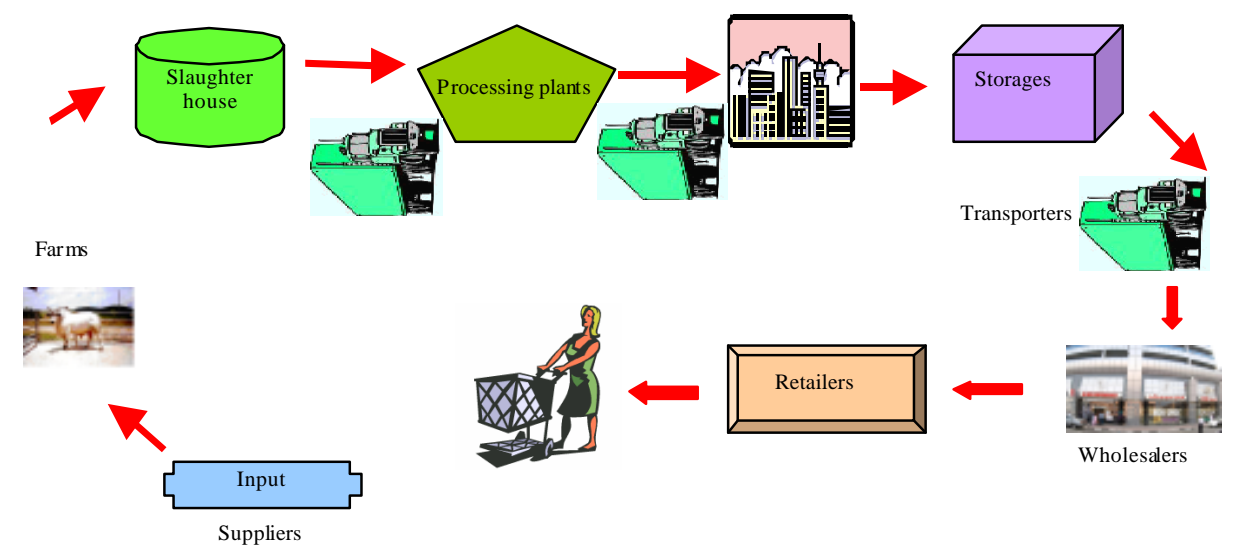

Fig. 1: Critical value chain

- Input traceability to determine type and origin (source, supplier) of ingredients used to create the raw product (seeds, stem cuttings and other planting materials, fertiliser, chemical sprays, irrigation water, livestock, feed) and materials (additives, chemicals) used for the post harvest handling, preservation and/or transformation of the basic raw food material into processed (reconstituted or new) food products. Input traceability includes the analysis of genetic constituents of products

- Disease traceability to determine the outbreak and monitor the epidemiology of biotic hazards such as bacteria, virus and other emerging pathogens which are potential risks to the humans through contamination of foods and other ingested products derived from biological and agricultural raw materials

- Genetic traceability to determine the genetic constitution of the product including variety, type, origin and alterations in the basic DNA structure

- Measurement traceability to relate individual measurement results (such as product quality and safety attributes) through an unbroken chain of calibrations to accepted reference standards

Based on Fig. 1, the following definitions will be used consistently through this study.

Traceability: The ability to track and/or trace product flows in both fresh production and an industrial distribution chain. Traceability implies that products are uniquely identifiable that at critical points in the production and distribution processes, the identity of product flows are logged and that the information is systematically collected, processed and stored (Meuwissen et al., 2003).

Tracking: The ability to follow products in real time. In monitoring a distribution process, one may want to know the current location of a product (for example online parcel tracking capabilities are now routinely used by most major courier companies) (Meuwissen et al., 2003).

Tracing: Reconstructing the historical flow of a product from stored records. Typically, when a consumer encounters a defective product, one may want to know the history of that product. This requires the analysis of registration and production records in a traceability database. There are two types of tracing activities:

Upstream tracing: The history of a product is reconstructed from the final destination of a product back to its origin. The important question here is: what are the origins of my product and can I identify which circumstance in that history is responsible for the defect at hand.

Downstream tracing: Raw material is taken as starting point and the products that contain that raw material are identified. If a batch of flour is polluted with dioxin which products are affected (Meuwissen et al., 2003).

Animal identification: The marking of individual farm animals or a group or lot of animals so that they can be tracked from place of birth to slaughter (Meuwissen et al., 2003).

Consumer: The end user of a product, service or technology (Meuwissen et al., 2003).

Customer: The party purchasing a product for distribution to consumers (Meuwissen et al., 2003).

Traceability and tracking systems: A traceability system provides a set of data that relate to both the where and when about the location of food and food ingredients along the production chain. However, there are various 


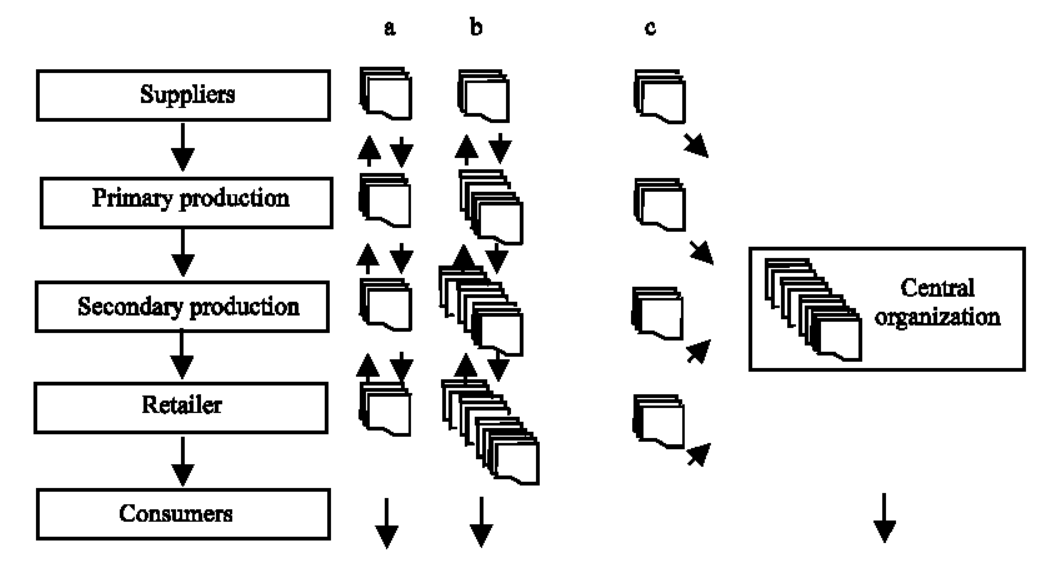

Fig. 2: Traceability systems in production chain (Meuwessen et al., 2003)

relevant understandings of traceability system (Gellynck and Verbeke, 2001). According to Gellynck and Verbeke (2001), tracing is the ability to trace food and food ingredients back along the production chain i.e., from the end user to the producer and even to the suppliers of the producer. Tracing is aimed at finding the history of a product, for example to allocate the source of contamination. Tracking refers to the ability to track food and food ingredients forward along the production chain. Tracking can be used to find and recall products that might present a serious risk to consumers health. McKean (2001) suggested that traceability systems can be set up with different purposes in mind to increase transparency in the production chain. More transparency is likely to increase consumers trust in food safety due to the increased amount of information about among others, production processes, food-safety controls, animals living conditions and the use of medicines. Increasing transparency is also likely to enhance the actual level of food safety as a result of the improved information flows throughout the chain.

On the other hand, Pettitt (2001) claimed that another purpose of implementing a traceability system can be to reduce the risk of liability claims, a proper traceability system is a valuable tool for companies to counterattack liability claims and to recoup claims from other participants in the production chain. Traceability systems can also be developed to improve recall efficiency. With an adequate system the quality of recalls can be improved which reduces costs and enhances the image of the production chain. These benefits can also be attributed to traceability systems that enhance the control of livestock epidemics. For traceability system to be adequate there are a number of requirements. First of all, all partners within the production chain should be identifiable also small producers and hobby farmers. The latter is especially important if the traceability system is also used for the control of livestock epidemics (Disney et al., 2001). Secondly, there should be a unique animal identification system (McKean, 2001), usually changed into an identification system for batches of animals as soon as the processing level is reached. Thirdly, an adequate traceability system requires a credible and complete (in the sense of what has been agreed on) information transfer along all participants of the production chain.

Three different types of traceability systems can be distinguished. These are outlined in Fig. 2. In system A, each link in the production chain gets its relevant information about the former link from the former link. The advantage of this type of system is that the amount of information to be communicated remains small which reduces transaction costs. The disadvantage is that this system is largely based on trust. Each link has to trust the former link on the quantity and quality of the information passed. Furthermore in case of an emergency, all links need a perfect administration in order to act fast. In system B each link gets the relevant information about all former links from the former link. With these systems the speed at which tracking and tracing can be handled is much higher than with systems of type A.

Moreover, because each link in the chain receives all other information the information can be controlled on completeness. Also the chain's transparency seems larger than with system A. A disadvantage is that the amount of information to be transferred increases per link. In the third type, system $\mathrm{C}$ each link of the production chain provides the relevant information to a separate organisation which combines the information of all links in the whole production chain. Such organisation can solve the matter of trust. Also tracking and tracing can in principle be carried out rapidly. Moreover, since the organisation is dedicated to the system the danger that the system is not well maintained because of lack of time or other resources is minimised. On the other hand, total costs may be larger. 


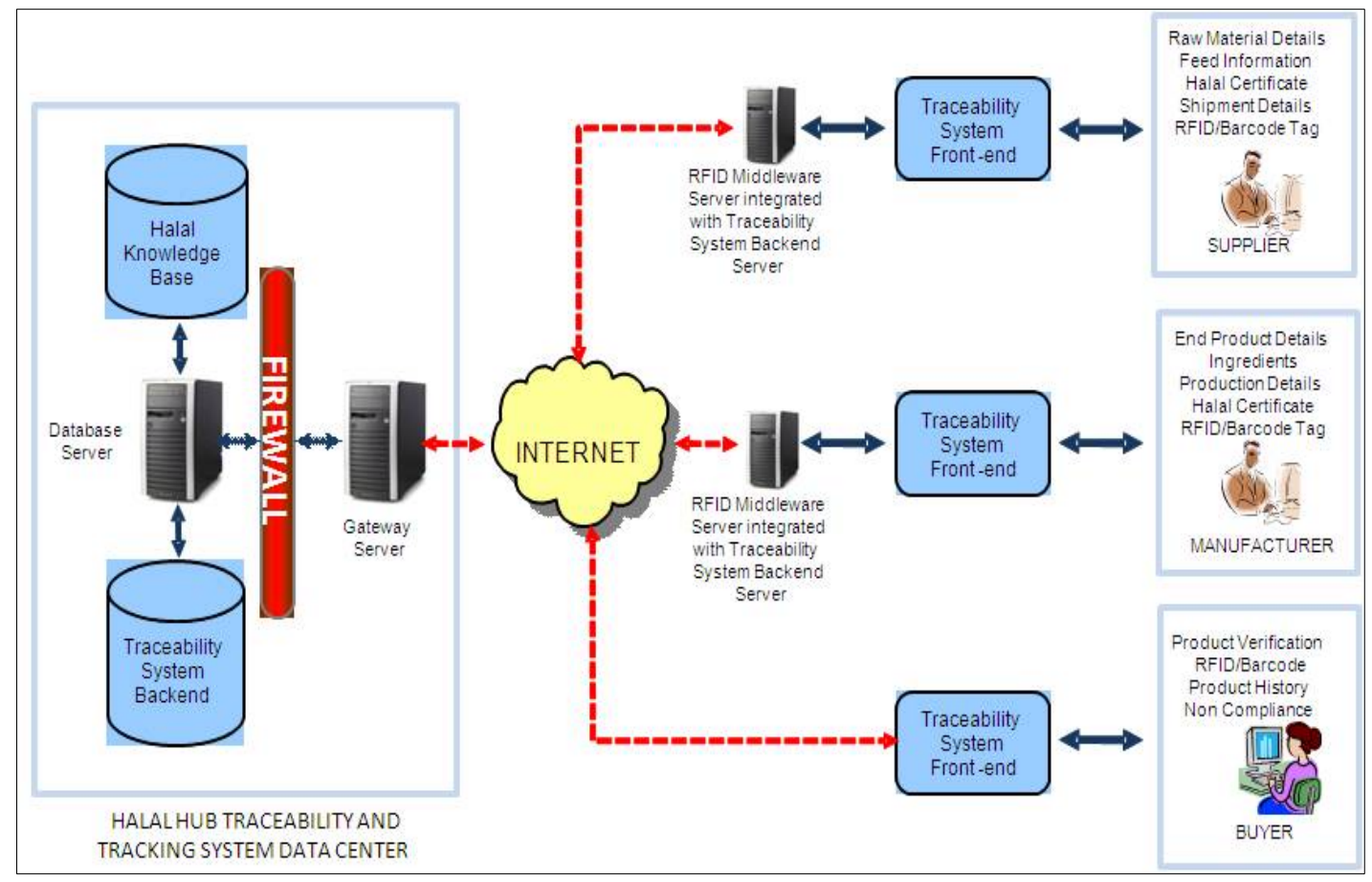

Fig. 3: Halal traceability system (http://www.pernec.com.my)

Halal traceability and tracking system in food supply chain: The Halal industry involves farm-to-table operations and this has led to the development of new links within the value chain, most notably in the area of information technology. Halal traceability system and Halal tracking system are emerging as lucrative areas in the global Halal market (Fig. 3). An effective traceability system in Malaysia is essential to mitigate the risks associated with Halal that can disrupt the international trade of Malaysian Halal food. Traceability systems function as a tool for communication making information available along the supply chain. In which it provides a set of data about the location of food and food ingredients along the production chain and these data relate to both the where and when issues. Following this, the key to an effective traceability system is good communication and management between successive links (one-up, one-down) along the supply chain. Specifically, tracing is the ability to trace food and food ingredients back along the production chain i.e., from the end user to the producer and even to the suppliers of the producer.

Tracing is aimed at finding the history of a product, for example to allocate the source of contamination (Meuwessen et al., 2003). Halal traceability systems can be set up with one purpose in mind in which to increase Halal transparency in the production chain. More Halal transparency is likely to increase consumers trust in Halalness of the food due to the increased amount of information about among others, production processes, food-safety controls etc., increasing Halal transparency is also likely to enhance the actual level of Halalness of the food as a result of the improved information flows throughout the chain. To run the Halal traceability system the various hardware requirements inclusive of Radio Frequency Identification (RFID) systems requirement will be adopted.

On the other hand, tracking is the ability to follow the path of a specified unit and/or batch of a product downstream through the supply chain as it moves between trading partners. Tracking system using RFID covers from the high-end business sectors to mid-range usage due to RFID's feasibility in the number of applications available today. RFID was discovered as early as 1935 which was during the World War II and it is known as one of the oldest tools available in the tracking technology today. Its capacity in tracking involving a complicated system to an ordinary system makes it one of the best tracking tools of its kind. In food and packaging industry all around the world, RFID tracking system is picking up momentum as it is being utilized to cater the demand of tracking inventory besides theft cases in the hypermarket. In Malaysia's food industry, food status especially involving Halal status is one of the prime area that has potential to leverage this technology. According to Azah et al. (2008), the Malaysian Muslim consumers are very much concern about the authenticity of Halal food products claimed by food producers. There are findings that revealed fabricating activities done by food 

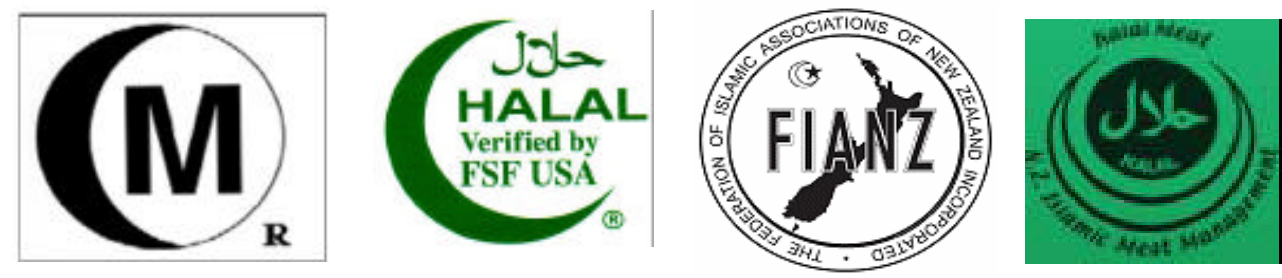

US halal logo

New Zealand halal logo

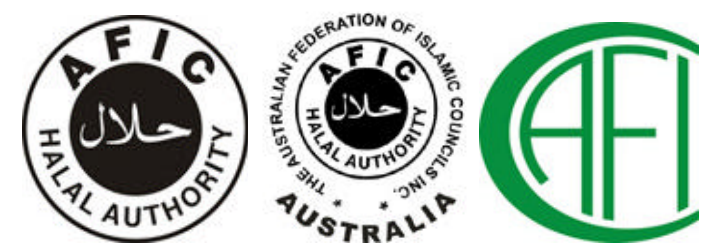

Australia halal logo

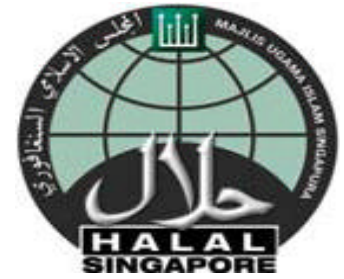

Sigapore halal logo

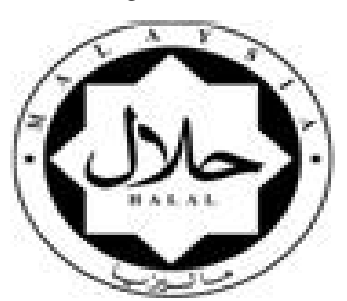

Malaysia halal logo

Fig. 4: Example of Halal logo towards Halal tracking

manufacturer to post Halal logo on their food packaging in order to attract Muslim users to buy their product, though in reality, the food manufactured from their premises are not certified by the authorize body (Azah et al., 2008). This is major problem in Malaysia market today. Halal brands, trademarks and logo hold no reliability or authenticity leading to possible doubts from the customers. Debate about tracking the food ingredients sold in the market is not only the worries but Muslim in Malaysia is also concern on the way of how the particular food is being prepared and how it is being packaged.

Realizing the potential market for Halal food industry since the last two decades, countries worldwide began to set up Halal authorities to provide Halal certification services (Fig. 4). However, a tracking system is needed to verify the Halal brand, trademark or logo on food packaging (Azah et al., 2008). According to them however, current Halal tracking approaches are manual, and just recently move towards the development of web-based information system that provides the list of Halal foods and Halal food search. Therefore, according to Azah et al. (2008), a tracking system is needed to verify the Halal brand, trademark or logo on food packaging.

They added that comprehensive tracking systems need to be employed to help depict related claims of the brand or the trademark on the package in a real time basis and in a trusted environment. With the power to track and trace items easily, RFID could be the best device to solve this problem. This is proven from studies done by Wu et al. (2006) and Brewer et al. (1999). They discusses on the RFID advantages and disadvantages where findings in the mid 90's still apply today, showing the significant and capability of RFID in the system tracking.

Problems in Halal traceability and tracking system: According to Azah et al. (2008), there are a few problems that arise when it comes to Halal tracking. They have discovered that firstly, there is no real time Halal tracking. Currently, few countries provide web-based Halal information services mainly focus on lists of companies and food products that has valid Halal certificates in a particular country. It is believed that more global application and database is needed in order to provide more information about all Halal food products available in the market. Secondly, the use of Halal certification logo are lacking of security in which logos can be copied, reproduced and sold by the perpetrators to companies that are not qualified to get Halal certification from the authority. Finally, there is no method to determine whether the food product came from the country which is stated on its packaging or otherwise. 
Therefore, a tracking system is needed to enable the monitoring of the movement of Halal food products from its origin countries to export destinations. In Europe, Port of Rotterdam is in fact in co-operation with other market parties including the Hecny Group and Vat Logistics to offer Halal supply chain solutions with full Halal certifications to realize the establishment of a dedicated ware house for Halal products which can also function as a European Halal Distribution Centre (The Halal Journal, 2006).

\section{CONCLUSION}

From this study, it can be concluded that Halal traceability and tracking comprise a very dynamic area in which new techniques are being introduced and standards rapidly evolve. Furthermore, the impact of traceability and tracking is expected to increase at the company and farm levels, the chain level and for society as a whole. Necessary transparency, control of livestock epidemics, increasing due diligence and withdrawing governments are leading contributors in this trend. Every each of the players has particular weaknesses when participating in the Halal markets. The important weaknesses are the lack of knowledge about Halal markets, Halal technology and the proper use of Halal inputs. Obviously, these are serious problems that can adversely affect their abilities to adopt the Halal traceability and tracking systems.

\section{RECOMMENDATIONS}

The study therefore suggest the following topics of emphasis in developing an economic research agenda:

Break-even point of Halal traceability and tracking: In an economic design of a Halal traceability and tracking systems, one should question the desired level of detail of the system i.e., is it efficient to be focused on a system as detailed as possible or is there some break-even point.

Acceptable level of risk in Halal traceability and tracking: A further consideration relates to the acceptable level of risk of Halal traceability and tracking systems. Acceptable level of risk is a common term in food safety systems. The main question here is whether supply chains need to be able to track and recall all products in one way or the other or whether they could for instance, rely on some alert system at the end of the chain.

Participation in Halal traceability and tracking systems: Whether efforts in Halal traceability and tracking systems reach the desired level of performance largely depends on the participation of the entire supply chain.

Participation in Halal traceability and tracking systems: A quantitative insight into the costs and benefits of Halal traceability and tracking systems still may not prompt farmers to participate.

Participation in Halal traceability and tracking systems: Still, there may be a problem of free riders throughout the chain. More insight is needed into the legal opportunities to effectively deter these individuals not only after widespread food safety scandals or livestock epidemics but also in a preventive manner.

Reconsideration of insurance: Halal traceability and tracking systems cannot exclude every risk. There is still the human factor, the possible introduction of new hazards and the risky and fraudulent behaviour of some individuals.

Communication with consumers: Various analyses have found that consumers willingness to pay for safer food is not straightforward. However, the problem may be one of communication. Key research questions in this regard might include: What information should be presented on the label (for example, HACCP or guaranteed safe).

\section{REFERENCES}

Azah, N.A., M.N.M.H. Nizam and M. Azmi, 2008. The users perceptions and opportunities in Malaysia in introducing RFID system for Halal food tracking. Wseas Trans. Inform. Sci. Appl., 5: 843-852.

Bates, S., 2004. Getting engaged. HR Magazine, 49: 44-51.

Brewer, A., N. Sloan and T.L. Landers, 1999. Intelligent tracking in manufacturing. J. Intel. Manuf., 10: $245-250$.

Disney, W.T., J.W. Green, K.W. Forsythe, J.F. Wiemers and S. Weber, 2001. Benefit-cost analysis of animal identification for disease prevention and control. Revue Scientifique Technique, 20: 385-405.

Folkerts, H. and H. Koehorst, 1998. Challenges in international food supply chains: Vertical coordination in the European agribusiness and food industries. Br. Food J., 100: 385-388.

Gellynck, X. and W. Verbeke, 2001. Consumer perception of traceability in the meat chain. Agrarwirtschaft, 50: $368-374$.

Henderson, H., 2001. Information: The great leveler. World Affairs, 5: 48-58.

McKean, J.D., 2001. The importance of traceability for public health and consumer protection. Revue Scientifique Technique, 20: 363-371. 
Meuwissen, M.P.M., A.G.J. Velthuis, H. Hogeveen and R.B.M. Huirne, 2003. Traceability and certification in meat supply Chains. J. Agribusiness, 21: 167-181.

Opara, L.U., 2003. Traceability in agriculture and food supply chain: A review of basic concepts, technological implications and future prospects. J. Food Agric. Environ., 1: 101-106.

Pettitt, R.G., 2001. Traceability in the food animal industry and supermarket chains. Revue Scientifique Technique, 20: 584-597.
Riaz, M.N. and M.M. Chaudry, 2004. Halal Food Production. CRC Press, USA.

The Halal Journal, 2006. Port of Rotterdam's Halal venture. http://www.Halaljournal.com/article/959/-port-of-rotterdam $\% \mathrm{E} 2 \% 80 \% 99$ s-halal-venture.

Wood, N., 2004. Customer value: Applying the first principle of lean. Manage. Services, 48: 14-17.

Wu, N.C., T.M. Nystrom, A.R. Lin and H.C. Yu, 2006. Challenges to global RFID adoption. Technovation, 26: 1317-1323. 